\title{
Desafios da aproximação do construcionismo social ao campo da psicoterapia ${ }^{1}$
}

\author{
Emerson F. Rasera \\ Universidade Federal de Uberlândia \\ Marisa Japur \\ Universidade de São Paulo - Ribeirão Preto
}

\begin{abstract}
Resumo
Nos últimos anos, o construcionismo social influenciou a construção de diferentes propostas terapêuticas. Buscando compreender de que forma as proposições construcionistas se encontram presentes no campo da terapia e como dão sustentação teórica a determinadas práticas psicoterápicas, este estudo analisou as propostas da terapia narrativa de White e Epston, da abordagem colaborativa de Harlene Anderson e dos processos reflexivos de Tom Andersen. Esta análise apontou para como estão presentes, de diferentes formas: a) a ênfase nos significados trazidos pelos clientes, b) a análise dos relacionamentos, c) o foco na potencialidade dos clientes e d) na terapia como co-construção, em consonância com as proposições construcionistas. Ao mesmo tempo, ressaltou a necessidade de reflexão sobre o caráter restrito da concepção de "social" e a sustentação de vocabulários modernos sobre o self. Esta análise convida a considerarmos tais propostas para além de uma perspectiva técnica, redimensionando-as como uma opção discursiva.
\end{abstract}

Palavras-chave: construcionismo social; psicoterapia; significado

\begin{abstract}
Challenges of using social constructionism in psychotherapeutic context. In the last years, social constructionism has contributed to the construction of different therapeutic proposals. Aiming to understand how cosntructionist assumptions theoretically sustain certain therapeutic practices, this study analyzed White \& Epston's narrative therapy, Harlene Anderson's collaborative approach and Tom Andersen's reflexive processes. According to constructionist assumptions, this analysis pointed to how it is presented, in these different proposals, a) an emphasis on the meanings brought by the clients, b) an analysis of the relationships, c) a focus on client's potentials and d) a notion of therapy as co-construction. At the same time, it pointed out the importance of reflecting about the concept of context used by those authors, as well as the sustenance of modern vocabularies of self. Finally, moving away from technical perspective, this analysis invites to consider those proposals as discursive options.
\end{abstract}

Keywords: social constructionism; psychotherapy; meaning

\section{Terapias construcionistas?}

$\mathrm{O}$ construcionismo social consiste em um conjunto variado de contribuições teóricas que tem ganhado espaço na literatura em Psicologia nas últimas duas décadas, inicialmente na Psicologia Social (Gergen, 1997, 1999; Spink, 1999), tendo se espalhado para outros campos, como o da Psicoterapia (Grandesso, 2000; McNamee \& Gergen, 1998; Niemeyer, 1998; Rasera \& Japur, 2001). Apesar das particularidades de tais contribuições, autores como Burr (1995) e Gergen (1999) afirmam que elas se articulam em torno de quatro idéias centrais, quais sejam: a ênfase na especificidade cultural e histórica das formas de conhecermos o mundo; o reconhecimento da primazia dos relacionamentos na produção e sustentação do conhecimento; a interligação entre conhecimento e ação; e a valorização de uma postura crítica e reflexiva.

No campo da psicoterapia, especialmente da terapia familiar, a utilização das idéias construcionistas tem se concretizado através de propostas de intervenção marcadas por uma nova descrição da postura do terapeuta e do processo terapêutico. Segundo alguns autores (Gergen, 1999; Gergen \& Warhuus, 2001; McNamee, no prelo), as terapias baseadas no construcionismo social têm promovido diferentes ênfases nas práticas psicoterápicas, quais sejam: (1) foco no significado: a investigação construcionista busca focar a atenção nas maneiras particulares pelas quais a pessoa se constrói nos relacionamentos e nos significados que orientam sua vida; (2) a terapia como co-construção: o terapeuta abando- 
na uma postura de especialista que dirige o processo terapêutico rumo a determinados significados, questionando a utilidade de seu vocabulário profissional para cada cliente com quem conversa e enfatizando as linguagens e os sentidos trazidos por ele. O papel do terapeuta, então, é o de criar condições para o surgimento de conversas que gerem novos sentidos em uma postura de colaboração, rumo à co-construção; (3) foco no relacionamento: a terapia construcionista busca a compreensão das questões trazidas pelo cliente, através de uma análise dos relacionamentos nos quais ele está envolvido e nos quais constrói determinados sentidos; (4) sensível a valores: o terapeuta construcionista considera que o relacionamento terapêutico é sempre pautado por determinados valores que influenciam na construção dos sentidos neste contexto. Alguns terapeutas chegam a propor formas de intervenção marcadamente políticas, como os terapeutas feministas e gays. Outros, contudo, apenas expressarão seus valores quando se tornar necessário na situação terapêutica; (5) ênfase polivocal: em oposição à idéia de uma única e verdadeira definição do real e à visão de um self unificado, a idéia de polivocalidade busca promover uma multiplicidade de formas de descrever um problema, bem como explicitar a multiplicidade de selves que nos habita nos vários relacionamentos nos quais estamos envolvidos; (6) foco na ação: baseados na idéia de que o processo de significação é contínuo e se transforma de uma relação para a outra, os construcionistas se preocupam com a possibilidade de utilização do discurso construído no contexto terapêutico, fora dele e com os resultados pragmáticos desta utilização propondo formas específicas de promover este processo de transferência; (7) atenção às potencialidades: a partir de uma crítica à noção de problema como algo que existe independente de nossas formas de significação, e à sua reificação nos processos de investigação psicoterápica, os construcionistas têm focalizado sua atenção em um discurso de potencialidades positivas e na construção de realidades futuras.

Segundo Gergen (1999), estas características podem ser encontradas em três formas típicas de terapia construcionista, quais sejam, a terapia narrativa, a focada na solução e a polivocal. Apesar de Gergen apontar tais propostas terapêuticas como típicas do construcionismo, a delimitação do que é uma terapia construcionista também é uma construção retórica, isto é, se dá segundo determinados objetivos contextuais, não se tratando, portanto, de uma descrição definitiva estabelecida por critérios a priori. Hoffman (2002) defende que as terapias pós-modernas podem ser mais bem identificadas às terapias narrativas e às terapias dialógicas/polivocais. Em outro texto, o próprio Gergen (Gergen \& Warhuus, 2001), ao buscar estabelecer diretrizes características das terapias pós-modernas, inclui na lista de terapias construcionistas abordagens tão distintas quanto a abordagem sistêmica de Milão e a terapia social de Newman e Holzman.

Evitando participar dessa discussão sobre uma definição do que é uma terapia construcionista, porém convidando a uma reflexão sobre essas diferentes propostas, o objetivo deste trabalho é descrever algumas propostas terapêuticas consideradas construcionistas e analisar de que forma as proposições construcionistas, suas ênfases e sensibilidades, dão sustentação teórica a determinadas práticas psicoterápicas e quais os desafios que apresentam.

Considerando este objetivo, selecionamos para análise três propostas influentes no campo, denominadas por seus autores ou pela comunidade de terapeutas como construcionistas sociais, quais sejam, a terapia narrativa de White e Epston, os processos reflexivos de Tom Andersen e a abordagem colaborativa de Harlene Anderson. A análise destas três propostas se orientará a partir de duas perguntas: "como descrevem a terapia, seu objeto e mudança?" e "qual o papel do terapeuta?”. Esta análise nos permitirá, então, identificar as descrições construcionistas privilegiadas em tais propostas, as semelhanças e diferenças entre as mesmas, bem como contextualizar as críticas a elas dirigidas e refletir sobre alguns desafios da aproximação do construcionismo ao campo das teorias psicoterápicas.

\section{Michael White e David Epston: narrativa e poder}

Estes terapeutas familiares, da Austrália e Nova Zelândia, indiferentes à denominação de construcionistas, constituem, sobretudo, representantes da virada narrativa neste campo (Epston, White \& Murray, 1998; White, 1994; White \& Epston, 1990). Baseados em uma metáfora textual, eles apontam que as pessoas, no esforço de dar sentido às suas vidas, organizam sua experiência em seqüências temporais, construindo um relato coerente de si próprias e do mundo. Este relato no tempo, esta narração, permite às pessoas um senso de continuidade e sentido em suas vidas, e faz com que passado, presente e futuro se mesclem na produção de qualquer narração. Nesta proposta, "uma história pode ser definida como uma unidade de sentido que oferece uma estrutura para a experiência vivida. É através destas histórias que a experiência é interpretada" (Epston et al., 1998, p. 119).

É importante notar que estas narrativas não são narrações secundárias sobre determinados fatos, ao contrário, determinam primariamente o que se considerará como fato. É neste sentido que tais narrativas são constitutivas, modelam a vida e as relações das pessoas, recortam o que deve aparecer, se destacar ou desaparecer. São elas que determinam o sentido que é dado à experiência, a seleção dos acontecimentos a serem expressos, a forma da expressão e os efeitos e direções da vida.

Nesta análise das implicações constitutivas da narrativa, os referidos autores separam a experiência vivida da narração sobre esta experiência. Apesar de tal narração dar sentido à experiência vivida, esta última é mais rica que o discurso. Narração e experiência vivida não se encaixam completamente; há frestas, espaços, indeterminações. No dizer de White e Epston (1990), “os relatos estão cheios de lacunas que as pessoas devem preencher para que seja possível representálos. Estas lacunas convocam a experiência vivida e a imaginação das pessoas. A cada nova versão, as pessoas reescrevem suas vidas" (p. 30).

A atenção construcionista à multiplicidade de vozes se dá de duas formas. Por um lado, todos os textos têm certo 
grau de ambigüidade, ou seja, a presença de significados implícitos, as diferentes perspectivas de leituras e as diversas formas de se descrever uma mesma situação produzem certa indeterminação que exige um ato interpretativo. Assim, o recontar de uma narrativa produz outra narrativa que inclui aspectos da anterior e a amplia. Por outro lado, há aspectos da experiência vivida que as narrativas dominantes não abarcam. Estes aspectos são denominados por White e Epston (1990) de acontecimentos extraordinários (unique outcomes). Estes "incluem toda gama de acontecimentos, sentimentos, intenções, pensamentos, ações, etc. que têm uma localização histórica, presente ou futura, e que o relato dominante não pode incorporar" (White \& Epston, 1990, p. 32).

Mas o que vêm a ser estas narrativas dominantes que abarcam apenas determinados aspectos da experiência vivida? A concepção de narrativa dominante se baseia na análise sobre a produção do conhecimento/poder e seus efeitos constitutivos, efetuada por Michel Foucault. Para este autor, experimentamos os efeitos constitutivos do poder por meio de verdades normalizadoras que configuram nossas vidas e relações, disponibilizando determinadas formas de ver, ouvir, sentir e falar sobre as coisas e o mundo, inclusive a si próprio. Tais verdades normalizadoras não estão referidas a fatos objetivos sobre as pessoas, mas a idéias construídas por meio do desenvolvimento de discursos de "realidade objetiva". Assim, por meio dessas verdades normalizadoras, há aspectos de nossas vidas que deixam de ser narrados, pois não se encaixam nos parâmetros descritos em tais verdades. A consideração do poder constitutivo destas narrativas dominantes traduz a sensibilidade construcionista desta proposta terapêutica aos valores promovidos por tais verdades.

Decorrentes desses aportes teóricos, várias são as implicações para a descrição do processo psicoterápico: a definição de problema, de mudança e como promovê-la. Segundo White e Epston (1990), o problema em terapia passou a ser definido a partir da idéia de que

as pessoas experimentam problemas, para os quais procuram terapia, quando as narrativas dentro das quais "relatam" sua experiência - e/ou dentro das quais sua experiência é "relatada" por outros - não representam suficientemente suas vivências. E, portanto, supomos também que nestas circunstâncias haverá aspectos significativos de sua experiência vivida que contradigam estas narrativas dominantes. (p. 31)

Buscando criar espaço para outras narrativas não marcadas por um problema, a intervenção por excelência desta proposta para a terapia é a externalização do problema. Ela se refere ao exercício de separar a pessoa dos problemas que elas enfrentam, através da coisificação/personificação destes. O problema se torna algo lingüisticamente separado, externo, menos constante e restritivo.

Ao permitir que a pessoa se separe do problema, ela pode passar a se descrever a partir de uma outra perspectiva que não a do problema, podendo, então, gerar uma outra descrição mais confortável a si mesma. Deixando de lado a história saturada pelo problema, a pessoa recupera sua capacidade de identificar outros fatos acerca de sua vida que contradi- zem tal história e proporcionam as pistas para a construção de novas histórias. Este foco construcionista nas potencialidades redimensiona o objetivo da terapia como sendo a "criação de histórias alternativas que incorporem aspectos vitais e anteriormente negados da experiência vivida" (White \& Epston, 1990, p. 46-47).

White e Epston (1990) elaboraram um modo específico de formular perguntas que facilita o desenvolvimento destas histórias alternativas, esses "relatos extraordinários". Esse processo de entrevista é denominado perguntas de influência relativa e é composto por dois conjuntos de perguntas: o primeiro conjunto busca descrever a influência do problema sobre a vida da pessoa e o segundo, a influência da pessoa sobre a vida do problema. Este modo de entrevistar é utilizado desde a primeira sessão e estimula a pessoa a se envolver na tarefa de se separar do problema.

Mas como definir o problema que se deve externalizar? Muitas vezes os clientes podem produzir descrições dos problemas que dificultam a identificação da influência do problema e dos acontecimentos extraordinários. Para White e Epston (1990), a definição deve buscar manter certa fluidez ao longo da terapia, deve ter um caráter mais geral do que específico, privilegiar termos populares e não técnicos, e ser mutuamente aceita pelas pessoas envolvidas no processo psicoterápico.

A partir da definição do problema e através das perguntas de influência relativa é possível identificar um acontecimento extraordinário, o qual pode ser procurado no passado, no presente e no futuro. Além disso, White e Epston (1990) ressaltam o uso da imaginação no desenvolvimento da externalização do problema, a qual torna o terapeuta mais sensível frente a determinados aspectos das histórias trazidas pelos clientes. À medida que o terapeuta conhece as reações comuns da pessoa e pode antecipar o que constituiria uma resposta diferente, extraordinária, ele tem condições de favorecer o desenvolvimento de relatos em torno de tais reações, estimulando, para isso, a imaginação de seus clientes.

Por meio do reconhecimento de acontecimentos extraordinários e da criação de explicações, redescrições e possibilidades que produzem novas narrativas, aumenta-se a resistência da pessoa frente aos efeitos do problema, bem como suas exigências, enfraquecendo-o. Nesse processo de construção de novas narrativas, a pessoa revisa sua relação com o problema, ressituando-o e redefinindo sua relação com o mesmo. Esta nova narrativa, ao separar a pessoa de uma história saturada pelo problema, produz uma sensação de liberdade para a ação, de capacidade de intervir no mundo e, assim, a pessoa torna-se capaz de assumir sua responsabilidade na construção de novas possibilidades.

Considerando a construção de novas narrativas sobre si mesmo e o mundo, o término do processo terapêutico, nesta proposta psicoterápica, é visto como um rito de passagem, ritual de transição de uma identidade, de um status social, para outro. White (1994) sugere que o final da terapia seria uma etapa que "se centra na reinserção da pessoa em um mundo social familiar e que promove a incorporação dos demais à celebração e ao reconhecimento de que a pessoa chegou a um destino ou a um status melhor que o anterior" (p. 206). 
Há diferentes formas de se proceder neste momento da terapia a partir de uma metáfora de reincorporação. Contudo, todas incluem a identificação e o recrutamento de um público capaz de legitimar a mudança e o conhecimento aí produzidos. Neste processo terapêutico produz-se, não apenas uma nova narrativa mais confortável e adequada à experiência da pessoa, mas, também, se constrói uma nova posição para si própria, na qual ela produz conhecimentos necessários e legítimos, tornando-a menos dependente do conhecimento de outros especialistas e aumentando sua autoridade em relação à sua própria vida. Esta forma de construir o término da terapia enfatiza o entendimento construcionista da terapia como uma forma de ação, bem como a importância dos relacionamentos na sustentação da mudança.

\section{Tom Andersen: processos reflexivos e outras descrições}

Andersen, autor autodenominado construcionista e que desenvolve seus trabalhos na Noruega, não possui uma descrição de um modelo terapêutico propriamente dito, de uma abordagem na qual seja apresentada uma definição de terapia, do problema e de mudança. Sua contribuição (Andersen, 1993, 1999) está mais diretamente ligada, no processo psicoterápico, a uma forma específica de se intervir que se relaciona a desenvolvimentos teóricos de vários outros autores. Andersen diz que o que ele propõe em terapia - a equipe reflexiva, ou melhor, os processos reflexivos - não é um método, mas, sim, uma maneira de pensar.

Esta forma de trabalhar surgiu em decorrência do desconforto de Andersen e seus colaboradores em fazer as intervenções terapêuticas nos moldes propostos pela abordagem de Milão na terapia familiar, na forma de apresentar as interpretações da equipe à família, a qual dava a eles a sensação de que suas interpretações poderiam ser percebidas como as melhores, numa clara relação de superioridade da equipe em relação à família. Uma primeira mudança nesta forma de trabalhar foi a incorporação de uma perspectiva de "tanto... como" em vez de "ou... ou" na apresentação das interpretações à família. $\mathrm{O}$ passo seguinte foi a inserção do convite à família para ver e ouvir como a equipe conversava sobre as conversas com a família. Iniciava-se a construção da proposta da equipe reflexiva e uma elaboração prática da colaboração construcionista.

Ao descrever a trajetória de construção desta maneira de pensar, Andersen (1999) apresenta um conjunto de idéias que a orientam. Podemos destacar desse conjunto cinco idéias principais. Primeiro, a de que não há uma coisa como algo em si; ela sempre o é como algo distinto de seu meio. Para ser definida enquanto coisa, como uma diferença em seu meio, é preciso fazer uma distinção. Sempre há mais diferenças do que se pode perceber. Sempre privilegiamos algumas distinções ou diferenças, em relação a outras. Estas diferenças se dão na linguagem, produzindo diferentes significados para as situações vividas. Encontramos aqui a ênfase construcionista no significado.

Segundo, a de que há três tipos de diferenças que produzem efeitos diversos: as diferenças comuns - as quais não propiciam mudanças; as adequadamente incomuns, que propiciam a abertura à mudança; e as inadequadamente incomuns, que propiciam o fechamento à mudança.

Terceiro, a de que a constituição de uma pessoa é estruturalmente forte e em mudança. Esta mudança ocorre como resposta a alterações em seu meio, sendo delimitada por suas possibilidades estruturais.

Quarto, a de que a multiplicidade de pessoas que uma pessoa é, decorre das diferentes formas de se autodescrever nas diferentes situações e contexto. À medida que a pessoa se expressa, ela se constrói de determinadas maneiras.

Quinto, a de que em uma conversa terapêutica há três conversas paralelas acontecendo ao mesmo tempo: duas conversas internas e uma externa. As conversas internas de cada falante buscam lidar com as idéias trocadas e com a participação na conversa externa. É um diálogo interno que permite à pessoa trocar, construir novas descrições, sem que sua integridade seja ameaçada. Nestas duas últimas idéias está traduzida a ênfase polivocal presente em muitas propostas construcionistas.

A partir destas idéias, Andersen (1999) desenvolveu a prática da equipe reflexiva. Trata-se de uma prática clínica na qual um consultor ou grupo de consultores - a equipe reflexiva - é chamado a participar de um sistema paralisado buscando criar condições, através de processos reflexivos, para que se possam produzir novas descrições e entendimentos das situações.

O formato da equipe reflexiva pode variar conforme as circunstâncias e preferências dos participantes. Contudo, de forma geral, ela pode ser de dois tipos: a equipe reflexiva formada apenas por um consultor e a equipe reflexiva formada por dois ou mais consultores. Neste último caso, o formato é o seguinte: dois membros da equipe reflexiva - o entrevistador e um outro - se encontram com o sistema paralisado, incluindo o terapeuta. Neste momento, são explicados os possíveis arranjos da sessão: as posições dos participantes, a equipe, as interrupções para diálogos sobre o que está ocorrendo nas conversas. Decide-se, então, conjuntamente com todos os participantes, o formato mais confortável para os envolvidos.

Quando a equipe é formada por apenas um consultor, este conversa com o terapeuta e combina quem será o entrevistador e quem será o observador. Explica-se, então, esta decisão aos clientes e combina-se que, em alguns momentos, o terapeuta e o entrevistador farão pausas para discutir as conversas que estão ocorrendo, ficando os clientes na posição de escuta. Solicita-se ao terapeuta que participe até onde julgar confortável. Decide-se, então, conjuntamente com todos os participantes, a adequação desta proposta.

As idéias apresentadas anteriormente e que orientam esta maneira de pensar - os processos reflexivos - implicam em determinadas diretrizes para a prática clínica, tanto para quem está como entrevistador, como para quem está como membro da equipe reflexiva. Descreveremos inicialmente as implicações para quem faz a entrevista.

Para Andersen (1999), uma conversa deve se iniciar com uma fase de preparação. Nesta fase, o entrevistador busca 
realizar uma investigação da história do encontro, quem o propôs, as aceitações e rejeições entre os participantes; e de como as pessoas gostariam de usar o encontro, tanto no que se refere aos assuntos como em que formato. Estas perguntas buscam, ao mesmo tempo, observar quem tem maiores reservas à realização deste encontro e, portanto, quem primeiramente deve expressar que o assunto está incomum demais; e dar a oportunidade a todos de expressar um compromisso com o encontro e suas percepções sobre o que e com quem se deve conversar. Estas perguntas orientam como será a sessão.

Durante a sessão, o entrevistador utiliza as aberturas no diálogo para fazer novas perguntas. À medida que ocorrem pausas no fluxo da conversa, o entrevistador faz perguntas sobre aspectos significativos do que acabou de ser dito. Ao longo da sessão, ocorrem inúmeras aberturas e cabe ao entrevistador escolher a abertura a ser usada, formulando perguntas que acredite contribuir para a expansão da conversa. Para isso, as perguntas devem ser adequadamente incomuns, o que o terapeuta busca saber observando a reação dos clientes frente ao que ele fala. Quando adequadamente incomuns, as perguntas tendem a gerar uma leve tensão marcada por algum tipo de mudança na atividade dos clientes, sem redução no fluxo de trocas durante a conversa. Assim, a identificação da adequação do que o terapeuta fala se dá tanto ouvindo como vendo. É neste sentido que Andersen (1993) chega a afirmar que talvez, em algumas situações, ver seja mais importante que ouvir.

As conversas propostas a partir de um modelo de equipe reflexiva promovem conversas internas e externas, possibilitando que as pessoas escutem e falem sobre as mesmas questões. Estas duas posições podem gerar diferentes perspectivas sobre o que se conversa. É justamente a transição entre estas duas posições que Andersen (1998) chama de processos reflexivos. A possibilidade de reflexão se afirma a partir da opção construcionista de criação de um contexto de colaboração entre equipe e clientes, no qual os significados são relacionalmente construídos.

No processo reflexivo, associado à formulação de perguntas, é importante que se desenvolva um sentido de copresença, uma disponibilidade em estar com o outro, estar junto, independente da fala ou do silêncio. Além de fazer perguntas e estar com o outro, ouvir consiste uma prática importante de tal processo. A posição de escuta, segundo este autor, poderia também ser chamada de posição reflexiva, pois, neste momento, é fomentado o diálogo interno. Mas como atua a equipe reflexiva na posição de escuta? Enquanto o entrevistador conversa com os clientes, os membros da equipe reflexiva apenas ouvem, sem fazer interrupções, perguntando ou fazendo sugestões. O entrevistador e os clientes são autônomos para decidirem o que conversam e como o fazem. Na posição de escuta, os membros da equipe buscam identificar aberturas, pensar sobre sua importância, porém, mantendo-se sempre disponíveis a outras aberturas que se mostrem mais relevantes. De forma geral, eles tentam refletir sobre os mesmos aspectos que orientam o entrevistador: outras descrições, possíveis explicações, conexões entre assuntos aparentemente díspares, transformações imagináveis e suas conseqüências para o sistema, características da forma e dos conteúdos da fala e conseqüências de partilhar determinadas reflexões.

A equipe reflexiva pode partilhar seus pensamentos, realizando uma troca de posições, através de um convite do entrevistador, que pode fazê-lo para saber as opiniões da equipe a respeito de determinado aspecto ou para dar uma pausa para o sistema paralisado.

$\mathrm{O}$ momento em que a equipe reflexiva partilha seus pensamentos define-se como um diálogo, no qual são feitos muitos questionamentos, perguntas e especulações sobre outras possíveis formas de descrever o que ocorreu, bem como sobre quais conversas podem ser mais úteis para cada tipo de assunto e situação. O que se busca, neste momento, é a multiplicidade de um diálogo e não o monólogo de um consenso fechado que busque orientar a família, impor algum sentido específico. Trata-se da ênfase construcionista de construção de novas potencialidades a partir da multiplicidade.

Após os comentários da equipe reflexiva, há novamente uma troca de posições. As trocas de posição ocorrem, geralmente, uma ou duas vezes durante uma sessão. Novamente, então, o entrevistador investiga, junto aos clientes, suas impressões da conversa da equipe reflexiva. Após todos terem expressado suas opiniões, o entrevistador pode também apresentar para discussão suas idéias sobre tal conversa. As perguntas do entrevistador na conversa que se segue são orientadas pelas mesmas diretrizes apontadas anteriormente.

Ao término da sessão é discutido o futuro das relações entre entrevistador, equipe reflexiva e clientes. Busca-se conversar sobre a necessidade de outros encontros, bem como da participação de outras pessoas.

Em todos os momentos da sessão, a cada intervenção dos participantes, é importante que se mantenha a concepção de que há muitas formas de se perceber uma situação e, portanto, de entendê-la e descrevê-la. Os processos reflexivos possibilitam considerar atenciosamente várias destas descrições na construção da pessoa. Além disso, constrói-se uma nova política das relações entre clientes e profissionais, marcada não mais por processos hierárquicos unidirecionais, mas por uma abertura, a partir do seu interior, do processo de construção dos sentidos realizado pelos profissionais.

\section{Harlene Anderson: colaboração e dialogismo}

O trabalho desta terapeuta familiar americana, a partir de sua parceria com Harold Goolishian, pode ser considerado como uma das tentativas mais explícitas de construção de um modo de fazer psicoterapia pautado pelo referencial construcionista, pela ênfase no caráter criativo da linguagem e por uma atenção aos processos de produção de sentido a partir de uma perspectiva hermenêutica (Anderson, 1997; Anderson \& Goolishian, 1988).

Um dos aspectos principais de sua proposta psicoterápica se centra na definição do sistema terapêutico como um sistema lingüístico. A ênfase construcionista na produção relacional do significado é traduzida de forma exemplar nesta definição. O sistema terapêutico não está referido ao produto de uma organização social (família, casal, etc.), 
mas a um produto lingüístico que existe nas descrições e narrativas, que se desenvolvem através da conversação, e que é reconhecido por sua relevância comunicativa, comumente associada ao problema que criou tal sistema. Assim, não é o sistema que tem, produz e gera determinados problemas, mas, ao contrário, os problemas que organizam determinados sistemas. Esta concepção tem uma implicação clínica marcante: participam do sistema terapêutico aqueles que estão no contexto lingüístico do problema, aqueles que conversam, descrevem, narram e produzem o problema, independentemente de fazerem parte de sistemas definidos socialmente.

Mas o que é um problema? As pessoas procuram terapia, costumeiramente, porque perdem seu senso de autocompetência para lidar com um problema. É algo que preocupa e se quer mudar; é interpretado e descrito de formas múltiplas e conflitantes; é único para a matriz conversacional do qual surge; está em fluxo, sujeito a revisão infinita. Em acordo com um foco construcionista no relacionamento, "um problema não é mais do que o que as pessoas envolvidas nas ações comunicativas estão chamando de problema" (Anderson, 1997, p. 76).

Contudo, é necessário que se produzam descrições dos problemas com as quais se possa trabalhar no sistema terapêutico. A partir da ênfase construcionista na colaboração, tais descrições não são produzidas tal como um diagnóstico tradicional, pois terapeuta e cliente participam, conjuntamente, da definição do problema. A responsabilidade do terapeuta é criar um contexto conversacional no qual seja possível estabelecer um processo de definição do problema. A descrição do problema precisa ser "trabalhável", ou seja, tem que fazer sentido para todos os envolvidos no sistema, deve possibilitar posições de respeito mútuo e deve permitir a participação de todos na transformação de seus sentidos, incluindo o terapeuta (Anderson \& Goolishian, 1988).

Entretanto, não se deve esperar a produção de uma descrição única, final e consensual ao longo deste processo de definição do problema. O importante é produzir conversações nas quais se ampliem os sentidos sobre o mesmo. À medida que a investigação sobre o problema ocorre durante o processo psicoterápico, este, como evento lingüístico que é, é dissolvido na linguagem, bem como se desfazem o sistema terapêutico e o sistema do problema.

O foco desta forma de trabalhar em psicoterapia não está no conteúdo - problemas e soluções -, mas no processo através do qual se conversa sobre algo. O que importa no sistema terapêutico é sua definição enquanto sistema produtor de sentido. Para Anderson (1997),

um sistema terapêutico é um tipo de sistema de linguagem relacional no qual as pessoas (no mínimo, um cliente e um terapeuta) geram significado umas com as outras (...) [o qual] está comprometido em desenvolver linguagem e sentido específicos para si próprio, específicos para sua organização e específicos para sua "dissolução" em torno do problema (p. 72).

Mas o que permite ao sistema terapêutico ser um sistema produtor de sentido? Segundo Anderson, outros sentidos são possíveis quando o sistema terapêutico se caracteriza como uma conversação dialógica. Para esta autora, uma conversação dialógica ou uma investigação compartilhada em terapia se iniciaria com o engajamento do terapeuta em um espaço dialógico interno consigo mesmo e, então, passaria a um diálogo externo com o cliente. Seria necessário, portanto, que o cliente entrasse em um diálogo interno consigo mesmo e em um diálogo externo uns com os outros. Isto propiciaria um engajamento do cliente em diálogos internos e externos fora do espaço terapêutico, bem como o terapeuta.

Através deste processo de conversação dialógica se dá o processo de mudança. Desta perspectiva, a mudança é uma conseqüência natural de um diálogo gerador e de uma relação colaborativa. À medida que a investigação compartilhada ocorre, novos temas, sentidos e entendimentos são conjuntamente produzidos, os quais não são mais definidos como um problema. A mudança se dá através das redescrições, das novas nuanças e dos diferentes significados atribuídos a situações vividas ou imaginadas.

Mas o que muda por meio desse processo? Para Anderson, esse processo de mudança possibilita o desenvolvimento de futuros selves. Através da produção de determinados sentidos e formas de se descrever as situações e o mundo, são geradas também outras formas de descrever a si próprio, as quais permitem modos de perceber e agir antes impedidos. Daí uma nova atenção para as narrativas individuais em primeira pessoa ao longo do processo psicoterápico. É a partir destas narrativas que os indivíduos derivam sua percepção da própria capacidade de agir socialmente.

A participação do terapeuta neste processo conversacional é descrita a partir de diferentes posições (Anderson \& Goolishian, 1988). De um lado, o terapeuta é um observador participante que busca situar-se em uma posição igualitária, e não hierárquica, em relação aos outros membros do sistema terapêutico. Nesta posição, ele constrói, colaborativamente com os outros membros, a realidade terapêutica, sem corrigir ou aperfeiçoar as descrições dos membros. De outro, na posição de facilitador participante da conversação, o terapeuta busca criar e sustentar uma conversação dialógica, não controlando o desenrolar da sessão, nem sendo o responsável pela direção da mudança. Sua posição, marcada pela ênfase polivocal promovida pelo construcionismo, não é a da simples neutralidade, mas a da multiparcialidade, a qual considera e trabalha com todas as visões presentes no sistema simultaneamente. Assim, suas próprias concepções, vieses e julgamentos também participam do sistema.

Estas duas posições são, posteriormente, sintetizadas através da noção de postura filosófica (Anderson, 1997). Esta é "uma posição autêntica, natural e espontânea que é única para cada relacionamento e cada discurso. (...) [mudamos] o pensamento em termos de nossos papéis e funções como terapeutas para considerar nossos relacionamentos com as pessoas com as quais trabalhamos" (p. 94). Nesta definição, busca-se a consideração da multiplicidade representada pela pessoa do terapeuta. Não se trata de uma técnica, mas um jeito de estar consigo próprio e com o outro.

O terapeuta se constrói na relação terapêutica, como vimos, através de uma parceria conversacional. Assim, há uma 
combinação das especialidades do terapeuta e do cliente. Este, na área do conteúdo, e aquele, no processo. Pautado na concepção da especialidade do cliente, cabe ao terapeuta criar um espaço e facilitar um processo de diálogo. A intenção principal do terapeuta, conforme Anderson, é estabelecer uma oportunidade dialógica.

Esta posição filosófica, antes de constituir um "método para a ação", é um "jeito de ser", ou seja, se permite e estimula que o terapeuta desenvolva seu estilo pessoal. O uso desta abordagem será distinto em relação ao terapeuta, à sessão e ao cliente. $\mathrm{O}$ que se exige é flexibilidade para se fazer o que a ocasião pede.

A relação terapêutica, seguindo uma inspiração construcionista, é sensível aos valores do terapeuta e dos clientes, sendo pautada pela reflexão e, por ser pública, por partilhar em voz alta os diálogos internos e privados, pensamentos, preconceitos, dúvidas, questões e opiniões. Segundo Anderson (1997), "refletir e me mostrar para o outro permite a mim e ao outro ter mais flexibilidade em lidar com opiniões naturais, múltiplas e algumas vezes conflitantes sobre as situações complexas apresentadas pelos clientes" (p. 103).

A responsabilidade no sistema terapêutico, a partir desta posição, é compartilhada com o cliente. O objetivo de se explorar esta responsabilidade relacional não é mudar o imperfeito ou resolver o conflito, mas ampliar as vozes admitidas na conversação. À medida que o terapeuta não se coloca como conhecedor da verdade e do melhor para o cliente, ele o convida a se responsabilizar conjuntamente pelas mudanças que ocorrerem.

Além de considerar as características da posição filosófica do terapeuta, Anderson (1997), a partir de conselhos dos clientes para seus terapeutas, aponta que, para promover uma oportunidade de diálogo e sustentar uma investigação compartilhada, cabe ao terapeuta uma postura de não-saber, confiar e acreditar, fazer perguntas conversacionais, ouvir e responder, manter a coerência, estar em sincronia e honrar a história do cliente.

A postura de não-saber representa um dos principais traços característicos desta abordagem psicoterápica. Ela está referida à postura do terapeuta na criação de um espaço dialógico na conversação terapêutica. Esta postura implica uma disposição do terapeuta à dúvida, não querer entender muito rápido, a evitar compreensões prematuras, a questionar o que já se sabe e a valorizar o conhecimento do cliente. Desta forma, o terapeuta evita fazer perguntas para verificar a verdade de suas realidades e não as do cliente, abandonando uma postura mais voltada a mostrar, contar, validar ou promover seu conhecimento ou preocupações. Esta postura implica também uma disposição ao risco de permitir ao cliente dirigir o contar sobre sua própria história, sem ser guiado pelas perguntas do que o terapeuta acha importante ser dito/ conhecido. Nas palavras de Anderson (1997), "um terapeuta precisa arriscar ser um aprendiz a cada novo cliente" (p. 135).

Através destas posturas, e não de técnicas instrumentais, ou procedimentos universais, é possível criar conversações dialógicas e relacionamentos colaborativos caracterizados por atos de conectar, colaborar e construir e que marcam processos de mudança para todos os envolvidos no sistema terapêutico.

\section{Refletindo sobre as propostas construcionistas em psicoterapia}

A apresentação de um conjunto de ações enfatizadas pelo terapeuta no processo psicoterápico, segundo cada uma destas três propostas específicas, possibilitou-nos visualizar o que poderia ser uma prática construcionista no campo da psicoterapia. Resumidamente, podemos destacar algumas idéias inovadoras propostas por esses terapeutas.

Na terapia narrativa de White e Epston (1990), a externalização do problema permite que a pessoa se separe lingüisticamente do problema e, ao identificar e explorar os episódios nos quais ela não se submeteu à narrativa dominante, pode criar uma nova narrativa sobre sua vida. Nesta proposta, o término da terapia, entendido a partir de uma metáfora da reincorporação, explicita a relação do sistema terapêutico com a sociedade em que está inserido.

Através dos processos reflexivos propostos por Tom Andersen (1999) cria-se uma nova política das relações entre clientes e profissionais na qual o partilhar das reflexões nas conversas terapêuticas imprime um novo jeito de se relacionar consigo próprio e com os outros, sejam terapeutas ou participantes.

$\mathrm{Na}$ abordagem colaborativa de Harlene Anderson (1997), a idéia de um sistema formado pelo problema redimensiona e complexifica a composição do sistema terapêutico. Nesta proposta, a postura de não saber e a proposição de uma parceria conversacional entre terapeuta e participantes contribuem para a transformação da relação entre os mesmos, na busca de posições mais igualitárias. Nesta proposta, a abertura à conversação substitui a busca pela solução.

Vemos assim como o foco no significado, na colaboração, no relacionamento, nas potencialidades e na ação, e a sensibilidade a valores e às múltiplas vozes, estão presentes com diferentes ênfases e de formas particulares em cada uma destas propostas. As proposições construcionistas não se traduzem de forma mecânica e homogênea, mas servem como contexto para a criatividade e inovação dos terapeutas na construção de diferentes recursos terapêuticos.

Contudo, as diversas tentativas de aproximação entre o construcionismo e o campo da psicoterapia encontram uma série de críticas referentes, sobretudo, à utilização das idéias construcionistas neste campo (Held, 1995; Kenwood, 1999; Lyddon, 1998). De um lado, os críticos consideram que muitos autores não têm uma postura construcionista em relação às suas propostas, correndo o risco de afirmá-las em detrimento de outras. Por outro lado, criticam a idéia dos "princípios" construcionistas serem traduzidos em um conjunto específico de diretrizes para a prática terapêutica. $\mathrm{O}$ risco da institucionalização dos discursos construcionistas, somado à tendência de identificá-los com determinadas práticas pode ter o efeito contrário ao pretendido por uma "teoria generativa" (Gergen, 1997), limitando e restringindo as possibilidades de conversação, ao invés de criar condições para a ampliação e expansão dos horizontes de entendimento. Se, por um lado, os autores das três propostas analisadas parecem não ser 
merecedores de tais críticas, por outro lado, essas críticas servem como alerta àqueles que buscam definições únicas de terapia construcionista e de técnicas específicas para a atuação do terapeuta.

Além daqueles riscos, acreditamos ser importante destacar outros dois desafios que se põem a uma aceitação mais abrangente do convite construcionista no campo da psicoterapia, quais sejam: a concepção do "social" presente nestas propostas psicoterápicas e os tipos de vocabulários sobre o self por elas promovidos.

Reafirmando a distinção entre dark e light constructionism (Danziger, 1997) e a conseqüente diferença entre os autores na ênfase dos aspectos macro e microssociais, respectivamente, as propostas terapêuticas analisadas neste artigo trazem diferentes formas de considerar as contribuições do contexto social para a conversa terapêutica. Entre as propostas anteriormente apresentadas, a terapia narrativa de White e Epston (1990), através do conceito de narrativas dominantes, oferece instrumentos para uma reflexão sobre a articulação entre o contexto macrossocial do qual participam clientes e terapeutas e o contexto microssocial das conversas terapêuticas. Nas propostas de Andersen (1999) e Anderson (1997) a origem histórica e social de determinadas descrições parecem ocupar um lugar secundário frente à ênfase na negociação local das mesmas. $\mathrm{O}$ enfrentamento deste desafio talvez possa contribuir com novos recursos para o trabalho terapêutico em contextos nos quais relações de estigma e discriminação social e desigualdade institucionalizada sejam predominantes.

Da mesma forma, a descrição de self subjacente a estas propostas ainda sustenta um foco individualista, seja na preocupação com o senso de autocompetência do cliente, na ênfase em sua experiência vivida, ou no cuidado com suas possibilidades estruturais, nas propostas de Anderson, White e Epston, e Andersen, respectivamente. Apesar de considerarem a natureza relacional do self, estes autores parecem ainda valorizar a importância dos discursos individualistas nas justificativas de suas propostas psicoterápicas. Mesmo reconhecendo a importância daqueles discursos, acreditamos ser importante cultivar a abertura a outros discursos sociais que possibilitem outras formas de entender e se relacionar no contexto terapêutico.

Ambas as preocupações presentes nas considerações anteriores talvez possam ser mais bem entendidas se tomarmos a terapia como uma prática histórica e culturalmente definida. Reconhecendo as origens modernas da psicoterapia, os objetivos de cura, a distinção entre conhecimentos especializados e leigos, podemos entender a sustentação destas formas de descrição do social e do self e reconhecer e encorajar as contribuições de tais propostas. Assim, apesar de ainda dialogarem com alguns parâmetros tradicionais da prática psicoterápica, tais propostas geram novas inteligibilidades que favorecem uma prática psicoterápica mais democrática e comprometida com sua própria reinvenção.

Entretanto, resta-nos o convite construcionista, como propõe Gergen (1997), a uma reconstrução e, mesmo, a uma "pesquisa do desalojamento", ou seja, uma pesquisa ou ati- vidade profissional na qual novos valores possam ser promovidos, levando o campo da psicoterapia a repensar seus limites e fundamentos em direção a uma prática em permanente transformação.

Assim, os riscos e desafios apresentados não buscam promover um abandono da utilização do construcionismo no campo da terapia, mas, ao contrário, contribuir para uma aceitação mais abrangente do convite construcionista, para uma postura de permanente reflexão que combata o autoritarismo de determinadas posturas e seja uma possibilidade de ação que leve ao diálogo e à expansão das possibilidades de relacionamento.

Dessa forma, reafirmando a primazia dos relacionamentos na produção e sustentação do conhecimento, tal como proposta pelo construcionismo social, podemos comparar as diferentes abordagens apresentadas neste artigo, compreendendo-as como opções discursivas (McNamee, no prelo) que podem ser utilizadas nas conversas terapêuticas. Nesta perspectiva, a teoria é considerada menos por seu caráter prescritivo do que por suas possibilidades de inspiração da ação do terapeuta.

Assim, podemos criar um modo mais produtivo de nos relacionarmos com estas propostas psicoterápicas se as considerarmos não como técnicas, ou formas instrumentais de se conversar baseadas na aplicação correta da teoria, mas como uma opção discursiva que nos permite, ao mesmo tempo, estarmos informados pelas idéias construcionistas, e mantermo-nos abertos às condições momentâneas da conversação e ao significado de certas negociações na sustentação do relacionamento terapêutico. Esta postura nos permite reconhecer a abertura e indeterminação do processo de produção de sentido e legitimar a importância da espontaneidade e do compromisso com o outro na sustentação dos relacionamentos humanos.

\section{Conforme nos ensina McNamee (no prelo),}

A construção social, como uma postura terapêutica, nos sintoniza com o momento interativo no qual a mudança terapêutica é possível. (...) A questão do que é terapêutico permanece aberta e indeterminada, assim como a conversação. (...) O que podemos fazer, contudo, é mantermo-nos abertos e atentos aos recursos conversacionais que utilizamos e a quais podem servir como alternativas úteis.

\section{Referências}

Andersen, T. (1993). See and hear, and be seen and heard. In S. Friedman (Org.), The new language of change (pp. 303-343). Nova York: Guilford.

Andersen, T. (1998). Reflexões sobre as reflexões com as famílias. In S. McNamee \& K. J. Gergen (Orgs.), A terapia como construção social (pp.69-85). Porto Alegre: Artes Médicas.

Andersen, T. (1999). Processos reflexivos. Rio de Janeiro: Instituto Noos/ITF. Anderson, H. (1997). Conversation, language and possibilities. Nova York: BasicBooks.

Anderson, H., \& Goolishian, H. A. (1988). Human systems as linguistic systems: preliminary and evolving ideas about implications for clinical theory. Family Process, 27, 371-393.

Burr, V. (1995). An introduction to social constructionism. Londres: Routledge. 
Danziger, K. (1997). The varieties of social construction. Theory and Psychology, 7, 399-416

Epston, D., White, M., \& Murray, K. (1998). Proposta de uma terapia de reautoria: revisão da vida de Rose e comentário. In S. McNamee \& K. J. Gergen (Orgs.), A terapia como construção social (pp. 117-138). Porto Alegre: Artes Médicas.

Gergen, K. J. (1997). Realities and relationships. Cambridge: Harvard University Press.

Gergen, K. J. (1999). An invitation to social construction. Londres: Sage.

Gergen, K. J. \& Warhuus, L. (2001). Terapia como construção social: características, reflexões, evoluções. In M. M. Gonçalves \& O. F. Gonçalves (Orgs.), Psicoterapia, discurso e narrativa: a construção conversacional da mudança (pp. 27-64). Coimbra: Quarteto.

Grandesso, M. (2000). Sobre a reconstrução do significado. São Paulo: Casa do Psicólogo.

Held, B. (1995). The real meaning of constructivism. Journal of Constructivist Psychology, 8, 305-315.

Hoffman, L. (2002). Family therapy. Nova York: WW Norton \& Company.

Kenwood, C. (1999). Social constructionism: implications for psychotherapeutic practice. In D. J. Nightingale \& J. Cromby (Orgs.), Social constructionist psychology: a critical analysis of theory and practice (pp. 176-189). Buckingham: Open University Press.

Lyddon, W. J. (1998). Social construction in counseling psychology: a commentary and critique. Counseling Psychology Quarterly, 11, 215-222.

McNamee, S. (no prelo). Therapy as social construction - back to basics and forward toward challenging issues. In T. Strong \& D. Pare (Orgs.), Furthering talk: advances in the discursive therapies. Nova York: Kluwer Academic / Plenum Press.

McNamee, S., \& Gergen, K. J. (Orgs.). (1998). A terapia como construção social. Porto Alegre: Artes Médicas.

Niemeyer, R. A. (1998). Social constructionism in the counseling context. Counseling Psychology Quarterly, 11, 135-150.

Rasera, E. F., \& Japur, M. (2001). Contribuições do pensamento construcionista para o estudo da prática grupal. Psicologia: Reflexão e Crítica, 14, 201-209.

Spink, M. J. (Org.). (1999). Práticas discursivas e produção de sentido no cotidiano. São Paulo: Cortez.

White, M. (1994). Guías para una terapia familiar sistémica. Barcelona: Gedisa. White, M., \& Epston, D. (1990). Medios narrativos para fines terapéuticos. Buenos Aires: Paidós.

Nota

1 Este artigo é parte da tese de doutorado do primeiro autor, sob a orientação do segundo autor, junto ao programa de Pós-graduação em Psicologia da Faculdade de Filosofia, Ciências e Letras da Universidade de São Paulo em Ribeirão Preto, com o apoio da FAPESP e CNPq.

Emerson F. Rasera, doutor em Psicologia pela Faculdade de Filosofia, Ciências e Letras da Universidade de São Paulo em Ribeirão Preto, é professor na Universidade Federal de Uberlândia.

Marisa Japur, doutora em Psicologia Clínica pela Universidade de São Paulo, é professora no Departamento de Psicologia e Educação da Faculdade de Filosofia Ciências e Letras da Universidade de São Paulo, em Ribeirão Preto. Endereço para correspondência: Departamento de Psicologia e Educação, Faculdade de Filosofia, Ciências e Letras de Ribeirão Preto, Universidade de São Paulo; Avenida Bandeirantes, 3900; Ribeirão Preto, SP; CEP 14090-910. Tel.: (16) 602-3735. Fax: (16) 602-3793. E-mail: mjapur@ ffclrp.usp.br 